\title{
Study of the Planning and Design of Tourism Highways Based on Green Ecological Concept
}

\author{
Dong Xin ${ }^{1 *}$, Yongxin Wang 2 , Quanliang $\mathrm{Xu}^{2}$, Hai Yan ${ }^{3}$ and Anqi $\mathrm{Lv}^{4}$ \\ ${ }^{1}$ Jiaoke Transport Consultants Ltd., Beijing, 100191, China/ Research Institute of Highway Ministry Of Transport, Beijing, 100088, China \\ ${ }^{2}$ Jiaoke Transport Consultants Ltd., Beijing, 100191, China \\ ${ }^{3}$ Beijing University of Technology, Beijing, 100124, China \\ ${ }^{4}$ Zhonglu Gongke (Beijing) Investment \& Consulting Co., Ltd., Beijing, 100000, China
}

\begin{abstract}
With the integrated development of transportation and tourism, building tourism highways has become a new direction leading the transportation industry and also an important sector of green transportation. Currently, the planning, design and construction of tourism highways in China are at their early stage, and there are few relevant codes, specifications, and standards concerning the planning and design. This paper introduces the connotation of Tourism Highways, and clarifies the scope and principles of the planning and design. It puts forward the planning and design concept of coastal tourism highways, and carries out planning and design practices for coastal highways in Guangdong based on the concept.
\end{abstract}

\section{Tourism Highway Related Concepts}

Tourism highways are mainly used for tourist travel. They connect the tourist attractions or belt highway corridors at roadside with tourist value, and integrate the main road and auxiliary facilities, service facilities, slow-traffic facilities, information interpretation facilities and landscape facilities. The highways have the composite functions of traffic, ecology, recreation, culture, education, etc. Tourism highways have four attributes: traffic, recreation, ecology and industry.

Coastal tourism highway is defined as the tourism highways along coastal side. The coastal line with rich tourism resources represents the critical feature of coastal tourism highway, becoming the focus of study and development. The specific coastal line tourism along the coastal tourism highways are the guide of the construction features and long-term supporting development, and it also has the potential to drive the corridor tourist economy.

\section{Scope and Principles for the Planning and Design of Tourism Highway}

Tourism highway is the product of the integrated development of tourism and transportation, so it has both transportation and tourism functions. The tourism highway shall provide the tourists with viewing tourism resources around while satisfying road accessibility and safe driving. It endows the highways with more functions of ecology, recreation, aesthetics and culture in addition to transportation. Therefore, the planning and design scope of tourism highways shall not only cover the highways, but also expand to the project's surrounding view area and the tourist areas (corridor areas) accessible by the trail system.

The planning and design of tourism highways shall observe the following principles.

\subsection{Functions}

The tourism highway intrinsically belongs to roads, playing the role of transportation means. Landscape planning and design shall give priority to smooth travel on roads and safe driving, and take in consideration the impact of landscape planning along the line on driver's vision and attention, guaranteeing safe and comfortable travel for the tourists.

\subsection{Ecological design}

The planning and design shall address natural ecological environment protection to protect the original landforms as possible; and follow the principles of "Maximizing ecological protection in design, minimizing ecological damage in construction, and maximizing ecological restoration in operation".

\subsection{Integrity}

Tourism highways generally extend for dozens of kilometers or even several hundreds of kilometers, connected to a number of tourist attractions along. They are distributed in a scattered way. In the planning and design, the landscape planning corridors shall be considered as a whole, and the construction shall focus

\footnotetext{
"Corresponding author's e-mail: 46935251@qq.com
} 
on one theme and purpose.

\subsection{Territoriality}

The planning and design shall fully integrate the local natural and cultural landscape, and location advantages, and demonstrate the local resource advantages via tourism highways, and expand local popularity.

\subsection{Recreation}

The highways shall fully consider the physiological and psychological needs of tourists, place emphasis on the services for tourists and base on tourist' needs for planning and design, striving for providing comfortable and humanized recreational facilities.

\section{Planning and Design Concept of Coastal Tourism Highway}

The planning and design of coastal tourism highway shall be considered from the perspective of spatial layout and road section classification.

\subsection{Spatial layout}

In terms of spatial layout, the coastal tourist highway shall comprehensively consider the vehicle circulation, slow-traffic system, service facilities, and visual landscape belts.

Vehicle circulation: providing carriers for self-driving cars and regional normal traffic, and give due consideration to the potential mixed non-motor vehicles. It is the main part of the coastal tourism highway as a linear corridor. The vehicle circulation shall use the linear indicators and system width that match the design speed, and take comprehensive consideration of various influential factors of traffic capacity, urban planning, and environmentally sensitive points. Considering the limitations of the terrain and tourism resources distribution, as well as the requirements of linear indicators and traffic efficiencies o the main vehicle line, a single main line can hardly meet the connection of all tourism resources. Embodiment of vehicle circulation is presented in straight main lines + lateral branch lines or connecting lines in a fishbone shape.

Slow-traffic system: mainly providing carriers for municipal commuter, recreational cycling, hiking, and recreation, including sidewalk for walking and cycleway for cycling. It is an important auxiliary system to the linear corridor of the coastal tourism highway. The design shall consider the functional requirements and landscape characteristics along the line, and adopt different design scheme, delivering flexible and diversified effects. In combination with the main line section itself, the slow-traffic system can be set separately, at the good-view side or at both sides of the main line. The slow-traffic system is consists of sidewalk and cycleway. For sections that are far from the countryside, the slow-traffic system can only have cycleway for riders and allow limited number of pedestrians. The slow-traffic system can not only serve as a carrier of tourism activities, but also be an extension of the vehicle circulation. As an important supplement to tourist traffic, it can guide tourists to areas that are inaccessible by vehicle circulation and experience the landscape along the route more deeply and intimately,

Service facilities: service facilities are the nodes on the linear corridor of the tourism highway. There are a wide range of service facilities at the coastal tourist highway, including: service areas that provides comprehensive service, parking and rest areas for short-time stays; parking areas and view platform at the scenic spots along the line; new tourist attractions, parks, and special town projects; convenient guidance facilities for tourists, etc.

Visual landscape belts: covering the range of people's vision in the vehicle circulation and slow-traffic system. It is the special display area of the coastal tourism highway that embodies the road landscape attributes. Full consideration shall be given to the visual effect along the line in the design, reflecting the landscape attributes of the coastal tourism highway. In this way, the tourists can enjoy sightseeing and recreation during driving. Based on the terrains and landscape characteristics of the road section, some targeted technical treatments will be made on the route layout in different methods. For example, set the route along the hillside near the mountain; raise the design elevation to obtain an open view of the landscape; run through the shelter forest in cycleway to the beach, obtaining the visual effect of the wave beach; design specialized landscape with wider green belts, making artificial landscape supplementary to the natural.

\subsection{Section classification}

Section classification refers to dividing the vertical space into various characteristics sections in line with the characteristics of the sections along the line. General road sections can be classified into three standard classifications, i.e. coastal urban section, tourist sightseeing section, and landscape transition section.

\section{(1) Coastal urban section}

The coastal urban section strikes along the urban and town developed areas. It can exert the function of urban transportation and distribution, and satisfy the slow travel and recreation needs of tourists. This section, to a certain extent, reflects the construction style of cities along. The urban coastal section lays its overall route in line with urban planning, and layout of the route is good for the development and utilization of land along.

The design of the vehicle circulation shall focus on the smooth flow of traffic. Due to the high network density of urban coastal sections and the high density of level crossings, the design shall take into consideration the impact of level crossings and crossings on the capacity of the main line and indicated theoretic advancing traffic capacity.

The slow-traffic system shall adopt the intensive design, and its combination with vehicle circulation will be more conducive to the utilization of land In terms of 
the cross-section layout, it is suggested to side green belts to separate the slow-traffic system from the vehicle circulation. With the relatively large traffic requirements of motor vehicles and non-motor vehicles in the coastal urban section, the isolation setting can better guarantee running safety.

In terms of visual landscape, the roadside of the coastal urban section is dominated by artificial buildings, and natural landscapes are relatively less. To improve the scope of visual sight, it is recommended to make efforts from unified planning and artificial green design of architectural styles along the line. Larger design width can be used for the green belts, and the plants planted in belts can be properly selected in design. Some featured landscape and square sculptures can be planned at the proper locations along the line. In the construction of supporting systems, the coastal urban section tends to integrate service functions with urban planning. The focus of study is on the combination of urban planning rather than its own supporting construction.

\section{(2) Tourist sightseeing section}

The tourist sightseeing section is an important scenic spot along the connected line, with beautiful landscape. This section attaches importance to tourists' sightseeing experience, and takes serving tourism as the key point in its design. Along the tourist sightseeing section, there are always mature scenic spots, e.g. temples, scenic areas, and resort hotels; or it may have good natural landscape endowments and development potentials, such as mangrove forest, beach, woodland, reef, and mountain.

The design of the vehicle circulation, on the one hand, shall pay attention to the connection of scenic spots and facilitate tourists to reach the spots; and provide branch lines and auxiliary transportation systems as supporting. On the other hand, the design shall make use of the natural landscape endowments to obtain optimal visual landscape presentation by means of view borrowing, introductions of perspective line and view opening. It is committed to achieve the "Traveling across beautiful landscapes, people are touring into the picture". The design pays attention to the display of the natural landscape in the driving vision, and avoids excessive pursuit for ultra-high design speed and linear indicators. It also focuses on travel experience and driving fun, and advocates to avoid large-scale excavations, protect the environment along the line and maintain the original look along the line.

The slow traffic system is a supplement to the roadway system. It is relatively flexible in setting, and can be designed to pass through sand beach and woods or in combination with scenic spots and parks. It can get closer to the best viewing angle of scenic spot, or go deep into the environment sensitive spot where is inaccessible for the roadway system.

The service facilities are also an important part of the tourist sightseeing section. The planning \& design level and service management capacity can affect the overall service level and tourism experience of the section.

In view of visual landscape, the main function is to fully integrate the natural landscape along the highway. As there are already beautiful natural sceneries along the tourist sightseeing section, in combination with the highway design in visual landscape, a wide and multi-angle visual field can be provided to display the natural landscape as far as possible. The transparency principle shall be adopted in section and greening design, and the human intervention shall be reduced as far as possible, so as to protect and display the natural sceneries along the highway.

\section{(3) Landscape transition section}

The landscape transition section refers to the section without prominent landscape or tourism characteristics, which is used to connect the above typical sections.

The utilization section of some implemented projects falls into this category: the main body of the highway has been basically completed, and the space for reconstruction and improvement is relatively small. Moreover, the current visual landscape conditions are unsatisfactory, and the development potential for roadside tourism is small.

From the design perspective, the roadway system focuses on the traffic function, that is, to make vehicles to pass quickly.

The slow traffic system is designed to set up in parallel with the roadway system with the purpose of saving land.

The design of service facilities mainly focuses on the following three points: (1) provide the necessary temporary parking function; (2) take into account the demands of refueling, rest and replenishment in combination with the length of road section; (3) give guidance of the front scenic spot and destination.

In view of visual landscape, the main principle is to unify and optimize the architectural style along the highway as far as possible. Control and develop the style of houses along the highway in a planned manner. For the built-up houses, the proper decoration and shape modification work can be carried out for adjustment.

\section{Case Study on Planning and Design of Guangdong Coastal Highway}

\section{(I) Project overview}

Guangdong is located near the mountain and by the sea, bordering the vast and fertile plains. Lingnan Culture (including Guangfu Culture, Chaoshan Culture, Hakka Culture, Qionglei Culture) blends with the marine culture. The $3368 \mathrm{~km}$ continental coastline connects 14 coastal cities. Guangdong's modern civilization lights the maritime Silk Road, and the collision of water and land reflects a clear and attractive blue ribbon. The transportation department of Guangdong explores a new model of green transportation development, implements the national overall strategy of "the Belt and Road", builds a Guangdong coastal economic belt, puts forward a new business type of "Transportation + Tourism" development, and develops the overall planning on Guangdong coastal highway construction.

\section{(II) Guiding ideology}

Comprehensively implement the spirit of 18th and 19th National Congress of the Communist Party of China, thoroughly understand and apply the ideology in series of important speeches by General Secretary Xi Jinpingas 
well as his new ideas and new strategies for governing the country, push forward the "Five-sphere Integrated Plan" overall layout and "Four Comprehensives" strategic layout in a coordinated manner, firmly establish and fulfill the new development concept, highlight the supply-side structural reform, take serving the people's livelihood as the basis, take supporting the development of Guangdong coastal economic belt as the guide, take promoting the "Transportation + Tourism" integration development as the priority, keep in line with the important dissertation on "golden age" of transportation development, vigorously advance the Guangdong coastal highway construction with more energy and charm, and provide a solid support for realization of "four perseveres, three supports, two in the forefront".

\section{(III) Overall planning scheme}

1. Build a longitudinal coastal corridor of thousand miles

Guangdong coastal highway is based on the layout planning of national southeast coastal scenic byway. It starts from Tielugang Village of Guangdong-Fujian junction in the east part of China, docking Fujian coastal great channel, connecting 14 cities including Chaozhou, Shantou, Jieyang, Shanwei, Huizhou, Shenzhen, Dongguan, Guangzhou, Zhongshan, Zhuhai, Jiangmen, Yangjiang, Maoming and Zhanjiang, linking the cities and towns, crossing the bays and waterways, adjoining the scenic spots and parks, facing the sea cliffs, passing through the farmlands and valleys, bypassing the sea islands, and ends in Baisha Town of Guangdong-Guangxi junction in the west part of China. It forms a trunk line in general parallel with G15 Highway and constructs a great corridor to boost and support the development of coastal economic belt.

In view of the difference of thousand miles corridor of Guangdong coastal highway, and in combination with the sequential landscape characteristics of scenic byway, the highway section and landscape space can be divided into 4 categories: urban coastal section, tourist sightseeing section, beautiful rural section, and landscape transition section.
Urban coastal section - highlight the modern civilization \& experience the cultural diversity: pass through the developed urbanization areas, focus on the smooth traffic, meet the function of urban traffic collection and distribution, and take into account the demand of tourists for slow travel and recreation.

Tourist sightseeing section - show the coastal landscape \& enjoy the leisure time: pass through the coastal scenic spots and areas of good visual landscape, focus on the ride comfort, and respect the demand of tourists for slow travel and recreation.

Beautiful rural section - feel the rural life \& stop in the characteristic towns: connect various nodes (especially the characteristic towns and cultural relics), focus on the transportation accessibility, and attach importance to the demand of tourists for experience and sightseeing.

Landscape transition section - look for beautiful sceneries \& obtain emotional and mental detachment: pass through the general areas of natural tourism resources and human tourism resources, focus on the smooth traffic, and attach importance to the dynamic landscape shaping and view borrowing in the viewing range.

2. Construct a coastal transverse development

\section{structure}

Based on the complex functions of coastal highway, especially the function as a linear landscape corridor, the space covered is extended to a certain transverse range in addition to the highway itself. The overall transverse spatial organization consists of four parts: roadway system, slow traffic system, visual landscape belt, and radiation belt. Generally, the transverse structure is dominated by the roadway system, including sightseeing and recreation, cultural perception, economic promotion, etc. The typical transverse spatial hierarchical structure and functions pushed inward by the sea are: the visual landscape belt, cycleway, green belt, roadway, auxiliary road, walkway, radiation belt, and the characteristic town.

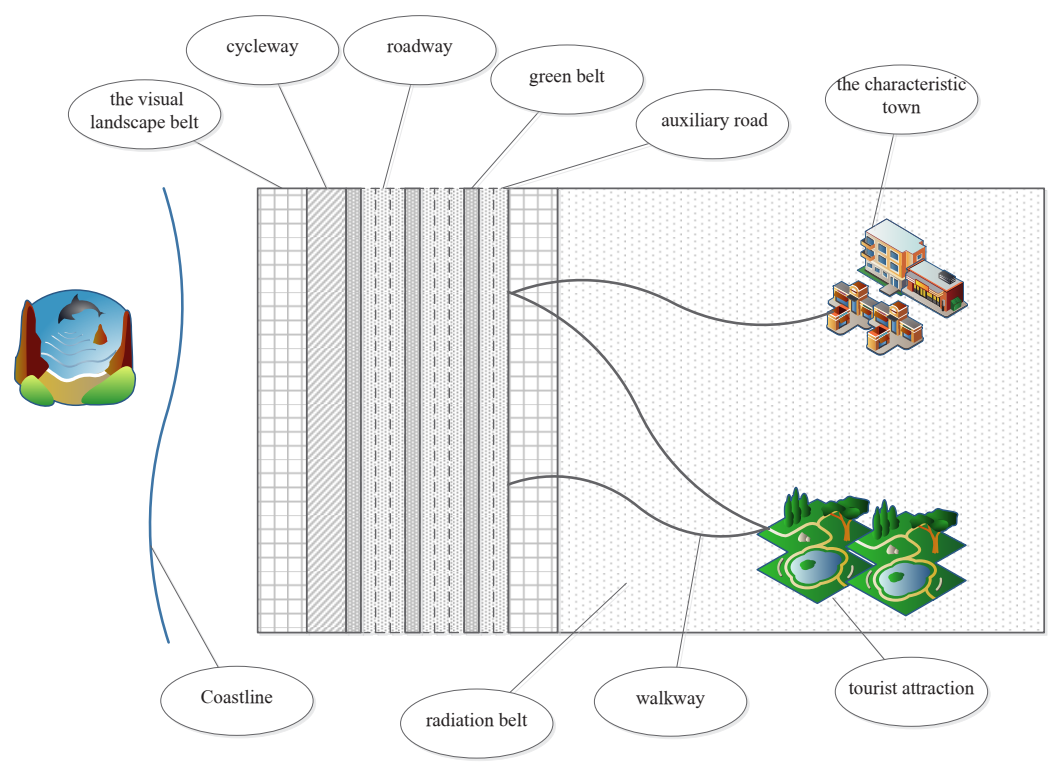

Figure 1. The typical transverse spatial hierarchical structure and functions by the coastal. 
Roadway system: it is the main body of coastal highway linear corridor, with a main function of providing carrier for self-driving and regional normal traffic

Slow traffic system: it is the important auxiliary body of coastal highway linear corridor, with a main function of providing carrier for leisure ride, hiking passage, recreation etc.

Coastal landscape belt: it is the belt area for visual landscape located on both sides of the coastal highway, and also the display area of the coastal highway landscape, natural and humanistic attractions, as well as the relatively concentrated area for recreational activities and tourist service facilities. The coastal side is called the "visual landscape belt", and the non-coastal side is called the "radiation belt".

Among them, the slow traffic system (cycleway and walkway) is an important part of tourism and leisure system supporting the coastal highway. Through building the slow traffic system attached to the coastal highway, continuing to boost the reputation of Guangdong greenway. The slow traffic system may go straight along with the roadway, or may be separated from the roadway to run through as a whole, so as to promote the charm of greenway throughout the Guangdong coastal highway, construct a "high, fast and slow" well-rounded travel system, bring a more perfect experience in subtropical customs of Guangdong coastal area, charming breath of Lingnan Culture and profound significance of rich history, and roam between the flourishing modern city and quiet countryside.

\section{Establish a coastal highway service system}

In order to further reflect the landscape value and connotation of coastal highway, it is necessary to establish a "comprehensive + general + simple" three-level service facility system.

Comprehensive service area: all-round and full-time; combine the layout of urban areas and major scenic spots along the coastal highway; and set up a comprehensive service area every $30-50 \mathrm{~km}$ on average.

General service station: characteristic tourism service; undertake the function of transferring tourists from landscape highway to connecting line, combine the towns and characteristic villages along the coastal highway, and set up a general service station every $20-30 \mathrm{~km}$ on average.

Simple service site: staying area for sightseeing. Provide the toilet and other basic services, and combine the general villages along the coastal highway and landscape node layout.

4. Strengthen the integration development of "Transportation + Tourism"

With the development trend of high-end global coastal tourism and high-quality mass consumption, based on the marine resources and Lingnan Culture, it is necessary to promote the "Ocean-Island-Coast" tourism three-dimensional development and "three major coastal areas, eight major coastal tourism groups, seven types of tourism functional units" differentiated development and integrated linking through Guangdong coastal highway planning and construction, push forward the upgrading and improvement of transportation service tourism from quantity to quality, implement the transformation from completing the single function of tourist transportation to enriching the tourist travel experience, implement the transformation from single "scenic spot" service to "all-for-one tourism" service, promote the transportation transformation and upgrading, and strive for the supply-side structural reform.

Table 1. The differential development of tourism in Guangdong.

\begin{tabular}{l|l}
\hline $\begin{array}{l}\text { Three coastal } \\
\text { tourist areas }\end{array}$ & Pearl River Delta coastal area, West Guangdong coastal area, East Guangdong coastal area \\
\hline $\begin{array}{l}\text { Eight coastal } \\
\text { tourism groups }\end{array}$ & $\begin{array}{l}\text { Huanzhujiangkou group, Chuan Island Guanghai Bay group, Hailing Island Moon Bay group, Shuidong } \\
\text { Bay Fangji Island group, Huanzhanjiang bay group, Daya Bay Renping Peninsula Group, Honghai Bay } \\
\text { Pinqinghu group, Nanao Island Shantou Bay Group }\end{array}$ \\
\hline $\begin{array}{l}\text { Seven functional } \\
\text { tourism units }\end{array}$ & $\begin{array}{l}\text { Coastal tourist resort, Coastal cultural tourism area, Coastal characteristic tourist area, Coastal } \\
\text { ecotourism area, Coastal tourism industrial park, International coastal leisure area, Red tourist area }\end{array}$ \\
\hline
\end{tabular}

\section{Conclusion}

With the rapid economic development and constant improvement of people's living standard in China, the demand for tourism and sightseeing is increasing. In addition, by virtue of low environmental cost and high added value, the tourism industry has become an important industry in the national economy. Tourist highway is equipped with dual functions of transportation and tourism, which is an important carrier to promote the integration development of transportation and tourism. As China has abundant coastal tourism resources, great attentions are paid to the construction study on coastal tourist highway in recent years. Therefore, the main tasks for future tourist highway work are to unify the concept of coastal tourism highway, develop the value evaluation method, popularize the new concept of construction, establish the standard specification of construction, and implement the national tourist highway planning, so as to demonstrate and lead the constructions all around the China to move in the right direction.

\section{References}

1. Ministry of Environmental Protection of the People's Republic of China, Ministry of Transport of the People's Republic of China (2014) Technical Points of Environmental Impact Assessment for Highway Network Planning (Trial) [R]. Ministry of Environmental Protection of the People's Republic of China, Beijing.

2. Qiang Zhu, Hailong Liu, (2006) Review on Research 
Progress of Green Channel Planning [J]. Urban Problems, (5): 11-16.

3. Jizhi Luo, (2009) Study on Mountain Ecological Highway Construction Based on Sustainable Development [J]. Western China Communications Science \& Technology, (09).

4. Xiao Chen (2012) Study on Coordination of Highway Network Structure Evolution and Regional Tourism Development in Hainan Province [D]. Yanbian University, Yanji.

5. Xinyu Zhao (2006) Study on Assessment Method of Tourist Highway Landscape Environment [D]. Northeast Forestry University, Harbin.

6. Haiwei Cheng, (2006) Design Considerations on Tourist Highway [J]. Shanxi Architecture, 1(32): 275-276.

7. Xinyou Fan, (2010) Reflections on China's Tourist Highway Construction from View of Ecological Civilization [J]. Ecological Economy, (02): 87-90.

8. Jiafeng Xu (2015) Study on Landscape Planning and Design of Tourist Highway - A Case Study in Zhejiang Ninghai [D]. Zhejiang A \& F University.

9. Ting Shang, (2010) Analysis on China's Tourist Highway Planning [J]. China Urban Economy, (9): 43-43.

10. Hua Ding, Xing Chen, Yunyang Zhang, (2013) Concept, Type and Effect of China's Tourist Highway [J]. Journal of Chang'an University, , 33(1) 